May 1998

\title{
Principles of family medicine
}

Riaz Qureshi

Aga Khan University, riaz.qureshi@aku.edu

Follow this and additional works at: https://ecommons.aku.edu/pakistan_fhs_mc_fam_med Part of the Family Medicine Commons

\section{Recommended Citation}

Qureshi, R. (1998). Principles of family medicine. Journal of Pakistan Medical Association, 48(5), 152-154.

Available at: https://ecommons.aku.edu/pakistan_fhs_mc_fam_med/222 


\title{
Principles of Family Medicine
}

\author{
Pages with reference to book, From 152 To 154 \\ Riaz Qureshi ( Division of Family Medicine, The Aga Khan University, Karachi. )
}

Family Medicine is the speciality of first contact with the patient, with an emphasis on providing comprehensive physical, psychological and social care for the patient and his family. The focus is on the patient, with the background knowledge of his family and not just on the disease entity, organ or system. Apart from curative care a Family Physician is in the best position to provide preventive care, promotion of health and rehabilitative care within the community and familiar sunoundings. In this age of sub-specialisation, a new kind of generalist called the 'Family Physician' is emerging throughout the world. The new generalist, however, is different from the old general practitioner. Instead of the undifferentiated bulk of the medical profession, defined chiefly by lack of special training and qualifications, there now is a well differentiated role and a defined set of skills ${ }^{1}$. The ten essential principles of Family Medicine care are Caring, Clinical competence, Cost-effective care, Continuity of cam, Comprehensive care, Common problems management expertise, Coordination of care, Community based care including prevention and research, Communication and counselling skills of high standard, Continuing medical education ${ }^{2}$.

\section{Caring}

The top most quality of a trained Family Physician is a caring attitude towards the patient, his family and the community. This is the cornerstone of a doctor-patient relationship, which is an essential ingredient in providing effective care ${ }^{3}$.

\section{Clinical Competence}

Caring without appropriate clinical competence is not enough for providing good quality care. An unqualified practitioner can also put himself across as caring but will lack the clinical competence to provide an acceptable level of care. To achieve a reasonable level of clinical competence forawide variety ofproblems, the present day Family Physician requires appropriate post-graduate training for 34 years. This level of training makes him acceptable as a specialist in his own right by the patients and the entire medical profession.

\section{Cost-effectiveness}

The management of an uncomplicated problem by Family Physicians in the community usually costs much less than being seen either at a hospital, due to high overhead costs orby a specialist who charges higher fees for his/her services. Family Physicians can provide considerable amount of care at a remarkably low cost.

\section{Continuity of care}

One well trained physician is ultimately responsible for all the problems including chronic ones of an individual and his family. This saves the patients going from pillar to post with increasing financial cost and for inadequate unconnected medical services.

\section{Comprehensive care}

Multiple problems of a patient can often be managed in one consultation by a well-trained Family Physician. This 'whole person' approach can obviously be cost-effective as well as time saving. A Family Physician is trained to look at problems comprehensively from the physical, psychological and social aspects. Family Physicians are also the main providers of personal preventive care, such as immunisation, child health surveillance, preventive medical checkups and health promotion, including advice on effects of lifestyle on health. They are also responsible for rehabilitative care in the community.

\section{Common problems management expertise}

A well trained Family Physician is an expert in managing common medical problems of patients of any 
age and sex in the community ${ }^{4}$. Chronic problems like diabetes, hypertension, asthma, backache, dyspepsia, anaemia, arthritis and infections of the respiratory tract, ear, nose, throat, urinaiy tract and skin can be managed effectively by family physicians. Consing other specialists for these problems can be costly for the patient and may also overburden the concerned specialist with uncomplicated problems.

\section{Co-Ordination of Care}

As first contact physician, the family physician is in the best position to provide the medical care for each and eveiy problem a patient presents. He/she can usually manage most of the patients problems himself/herself and can refer the remaining problems to the concerned specialist. It is often difficult for patients themselves to decide who would be the best specialist or health care provider for their particular problems. Itis the family physicians responsibility to guide the patient through the health care system and act as a gate keeper for good quality, cost effecitve care.

\section{Community based care and research}

Comprehensive care at the doorstep is the hall-mark of the care provided by a Family Physician. This can include not only curative, but preventive measures within the community and specified population. Research in the community setting is often more appropriate for the health care needs of the great majority of the population. A research on Hospital based patients is often more relevant to the needs of the small percentage of the patient population and is less likely to produce knowledge for effective prevention of disease.

\section{Counselling and Communication skills}

A physician-patient rapport is needed for successful patient education and counselling.

Researchdemonstmtes that improved counselling and teaching of patients can improve compliance. The more communication skills are used and perfected, the more effective and satisfying the clinical encounter will be, for both the patient and the Family Physician ${ }^{5}$. All clinicians are counsellors and educators but the Family Physician has a distinctive need of a high standard in these skills.

\section{Continuing Medical Educatio (CME)}

A Family Physician requires a good breath of knowledge to solve each and every problem ofhis/herpatients presented to him, either by himself, or arranging an appropriate referral. This role obviously requires updating of knowledge and learning skills throughout his/her life time of clinical practice.

\section{Training Family Physicians for Pakistan}

A workshop attended by high government health officials, medical educationists, deans and principles of medical unviersities and colleges was held in June 1994 to focus on augmenting communityoriented teaching in all the medical colleges in Pakistan. Apart from emphasising the need for strengthening the content of family medicine and primaiy care in the undergraduate curriculum, this forum also recommended the establishment of departments of Family Medicine in all medical colleges of Pakistan. These steps will help to produce physicians with greater insight, knowledge and skills for solving and managing the common and chronic problems which make up the bulk of the health problems inthe community.

In November, 1993, The Aga Khan University established the first organised three-year residency training programme in Family Medicine in Pakistan. This programme has already been recognised for the FCPS in Family Medicine and theMRCGP (UK) examinations. There isadesperate need to establish similar residency training programmes in other medical colleges, in the public and private sectors throughout the country, so that appropriately trained Family Physicians who can provide caring highquality and cost- effective medical care are made available.

\section{Conclusions}


Family medicine is identified not by one of its principles, but by all of its principles. All of its principles put together make a very powerful and convincing therapeutic agent that can be used to help the patient no matter what the disease, sex or age.

Over the past few years, the principles of family medicine have begun to be recognised, valued, taught and learned in some of our medical colleges. But there is still lot of work to be done. Our primary health care system needs revamping, and the principles of family medicne need to be more broadly applied. Just as principle6 of cardiology, endocrinology or surgery can be used in other disciples, the principles of family medicine can also be used by other disciplines. The ten principles mentioned above form the foundation for solving clinical problems. The seriously ill patient or the patient with chronic disease usually requires a more extensive use of the principles.

\section{References}

1. Sloane. D.S., Slatt, L.M. and Curtis, P. Essentials of Family Medicine (2nd Ed.). Baltimore/London, Williams and Wilkins, 1993, pp. 3-8.

2. McWhiney, 1.R. A textbook of family medicine, 2nd Edition, Oxford, Oxford University Press, 1989, pp. 1-25.

3. Balint, M. The Doctor, His patient and the Illness. Revised ed, New York, International Universities Press, 1964.

4. Driscoll, E., Bope, T., Smith, C.W. et al. The Family Practice Desk Reference (2nd ed). Mosby Year Book. 1991, pp. 1-17.

5. Levenstein, J.H., Mc-Cracken, E.C., Mc-Whinney, I.R. eta!. A model for the doctor-patient interaction in Family Medicine from Fam. Pract.,1986;3 :24-30. 